\title{
Sororidad en los procesos de envejecimiento femenino*
}

\section{Sorority in female aging processes}

\author{
Lucía Pérez Sánchez ${ }^{*}$ \\ ORCID 0000-0003-1614-7587 \\ Marcela Rábago De Ávila \\ Mayra Guzmán Ortiz \\ Rosario de Jesús Zamora Pérez \\ Universidad Autónoma de Nayarit, México
}

Recibido: 12 de enero de 2017 Revisado: 16 de marzo de 2017 Aceptado: 24 de mayo de 2017

\section{Resumen}

La sororidad engloba las prácticas de colaboración y soporte en las relaciones entre mujeres y es el espacio propicio para la construcción de nuevas formas de signifi ar la vejez femenina. El objetivo de este estudio cualitativo fue describir y categorizar los tipos de configuraciones vinculares que se mantienen y los que se han transformado en pro a la sororidad en los procesos de envejecimiento femenino, por medio del análisis narrativo de una entrevista profunda grupal. Los resultados muestran la necesidad de implementar políticas y acciones en aras de disminuir el ageism con relación al envejecimiento de mujeres. La construcción de la sororidad ayuda en el empoderamiento colectivo en pro de su género. La sexualidad de la mujer mayor sigue siendo un tema pendiente en la agenda de la investigación y la discusión en los estudios feministas, lo que nos lleva a concluir que, a pesar de la existencia de diferencias individuales en los propios procesos de envejecimiento, las mujeres se experimentan y

Artículo de investigación. El artículo presentado es parte de un proyecto titulado: CONSTRUCCIÓN DE COMUNIDADES CON IDENTIDAD AUTOGESTORA, el cual cuenta con financiamiento total por parte del Programa para el Desarrollo Profesional Docente, para el Tipo Superior (PRODEP), con número de registro: UAN-EXB-323. y con registro ante la secretaria de investigación posgrado de la Universidad Autónoma de Nayarit, con el número: SIP16-149, con una vigencia de Agosto 2016 - Agosto 2017. http://dx.doi.org/10.15332/s1794-9998.2018.0001.01

Correspondencia: Profesora Investigadora Lucía Pérez Sánchez, Universidad Autonoma de Nayarit, México. Dirección postal: Rió Bravo No. 85 Col. Los Fresnos, Tepic, Nayarit; México. Correo electrónico: lucia@systemica.com.mx 
comparten en una misma condición histórica, por ello es en colectivo que la acción de la sororidad se pronuncia como vía en la generación de nuevas narrativas preferidas por las mujeres. Finalmente, se expone una propuesta para trabajar la percepción del cuerpo femenino en el proceso de envejecer, y la construcción de la sororidad, desde las prácticas narrativas de White y Epston.

Palabras clave: Sororidad, envejecimiento femenino.

\section{Abstract}

Sorority encompasses the practices of collaboration and support in relations between women and is the propitious space for the construction of new ways to signify female old age. We present results of a qualitative study using focus groups, which aimed to describe and categorize the types of relational configurations that remain unchanged or change towards sorority in the female aging process. Findings describe the need to implement actions to reduce ageism, not only in terms of the experiences women go through, but also towards aging in general. One of the measures we can take is undoubtedly the construction of women circle sorority, which leads to collective empowerment of gender. The female body is a focus of attention in terms of what it lives and experiences, and the right to have love and sexuality throughout life is also highlighted. We then created an intervention proposal to work on the perception of the female body and its experience in the aging process. The proposed intervention is a workshop, based on the narrative model of Michael White and David Epston.

Keywords: Sorority, female aging.

\section{Introducción}

\section{Sobre lo que se define con relación a la sororidad}

La sororidad se define como la manera en que las mujeres se organizan, se apoyan y así de esta manera se propicia el intercambio de experiencias. Hace alusión al concepto de hermandad, que posibilita la resignifi ación y coexistencia entre mujeres. Nace en el seno de los movimientos feministas y es un aporte de una figura académica referencial del feminismo contemporáneo como lo es Marcela Lagarde (1997, 2013). Sororidad no se suscribe solo al ámbito familiar, sino a todo escenario en donde las mujeres tengan convivencia o interrelaciones. El término surge desde la perspectiva feminista, que se deriva del latín soror, hermana, e idad, relativo a la relación paritaria entre mujeres, es decir, se trata de una alianza entre mujeres que propicia la confianza, el reconocimiento recíproco y el apoyo (Lagarde, 2013).
Desde la perspectiva de los estudios de género, elabora una reflexión en relación al origen del concepto de sororidad; el cual constituye el eje que articula estas dos categorías: relaciones entre mujeres y envejecimiento, y pone en la mesa de análisis y reflexión el cuestionamiento sobre: ¿por qué si hay un reconocimiento de igualdad en valor, derechos, dignidad y libertad entre hombres y mujeres se tienen que recalcar estas últimas?, a caso el sentimiento de acompañamiento en la búsqueda del bien común femenino es algo que deba evaluarse y reflexionarse?; a lo que se considera que sí.

En este tenor es que Pagaza (2014) plantea la necesidad de un resarcimiento y comprensión para reencontrar el origen emocional de los vínculos con otras mujeres en una relación de semejantes. Para esto propone llevar al plano de la reflexión lo que han signifi ado cada una de las mujeres que se han cruzado en cada historia de vida, de tal manera que se ratifique o se resignifiquen los vínculos primarios. 
Con lo anterior, se da pie a valorar la posibilidad de construir una cultura de la sororidad, como una forma de contribuir a la desconstrucción de prejuicios y estereotipos reproductores de maneras y formas restrictivas, excluyentes de aquellas mujeres que entonces y ahora, que aspiran a condiciones dignas y legítimas de existencia. La sororidad entonces personaliza una elección trascendental y vital, que simboliza e identifi a una nueva posibilidad entre mujeres de relacionarse, a pesar de sus mundos diversos y trayectos diferentes.

\section{Una aproximación necesaria en el estudio del envejecimiento}

La perspectiva de género en el estudio del envejecimiento es una necesidad dentro de la investigación y la teoría que lo estudia. El proceso de envejecer entre hombres y mujeres es diferente, la vivencia y experiencia de vejez es una situación personal y vital claramente opuesta.

Pensar en un envejecimiento diferenciado lleva a reflexionar en temas diversos tales como: evolución en los roles tradicionales de género, sexualidad, salud, menopausia, economía, violencia, vulnerabilidad, pobreza, entre otros, que ayudan a entender que el proceso de envejecimiento se constituye de manera singular y colectiva, es decir, cada sociedad, cultura, época histórica construyen sus modos de envejecer, por lo cual su estudio se conformará en observaciones de varios niveles. Atribuyendo así un grado de complejidad (Morin, 2004; Salvarezza, 1988) el cual no puede homogenizarse pues solo fomenta estereotipos negativos y discriminatorios de las personas mayores (ver fig. 1).

Figura 1.

Aproximaciones en el estudio del envejecimiento (Pérez, 2016; basado en Freixas, 1997; 2004 \& Zarebski, 2005).

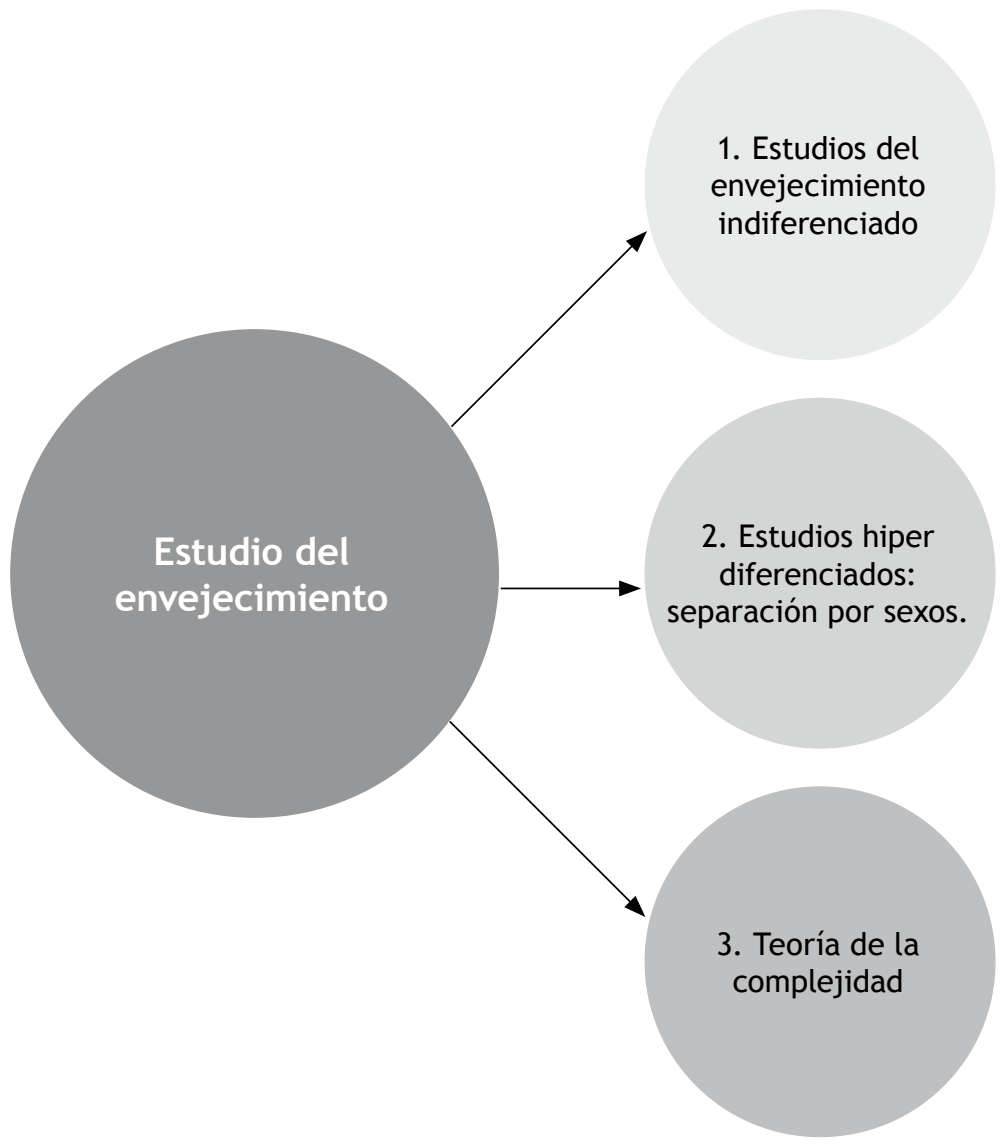

- Abordajes homogenizados

- Sexo y edad no son relevantes
- Explicaicones cuasi únicas para cada sexo

- Repetición de discursos patriarcales.
- La persona como ser activo en su proceso de envejecimiento

- influencia de lo social, lo histórico y lo cultural. 
Como se puede apreciar en la primera aproximación existe un sesgo en la perspectiva de género, la edad como el género no son relevantes en los estudios del proceso de envejecimiento, y en la segunda se perpetúan estereotipos patriarcales, realizando explicaciones a partir de roles tradicionales. A saber, en la mujer se analiza desde una visión reductiva de su sexualidad haciendo referencia a la reproducción (menopausia exclusivamente y nido vacío); y por otro lado en los hombres se expone las temáticas referentes a la jubilación y la finalización de la vida productiva en el ámbito económico. En la teoría de la complejidad, por su parte, se aporta una referencia de cambio y evolución dotada por aspectos sociales, históricos y culturales en constante metamorfosis, no sesgada, en la que se da cuenta del significado de los procesos psicológicos de las personas, es decir la subjetividad de la persona que envejece.

La tesis central de la necesidad de incluir esta perspectiva en el estudio del envejecimiento, es que cuando se estudia la vida de las mujeres, la psicología del desarrollo de las mujeres no puede derivarse de la de los hombres. De tal forma que uno de los retos que deberá afrontar la teoría psicogerontológica y evolutiva es dar cuenta de la complejidad del proceso de envejecimiento en la población femenina y masculina.

Esta tarea no es fácil de llevarse a cabo, en la que la investigación psicológica deberá ayudar a conceptualizar marcos teóricos alternos a los que hasta hoy se ha explicado el desarrollo. Para así modifi ar viejos esquemas unifi adores, negativos, patriarcales y androcéntricos que han servido para hacer invisibles a las personas en la última etapa de la vida y, en especial, a las mujeres desde hace mucho tiempo.

\section{Envejecimiento y el cuerpo de la mujer}

En el envejecer se tiene la oportunidad de reflexionar y preguntarse cómo es que se llegó a ser femenino o masculino. Hablar del envejecer en la mujer es hablar del envejecer del cuerpo, de una belleza situada y signifi ada socialmente en un cuerpo físico, que en este proceso se trata de ocultar a modo de invisibilizar. El rechazo social por el cuerpo de la mujer mayor va a niveles sorprendentes cuando el cuerpo de la mujer está condicionado a un mercado regido por la juventud y la delgadez. Butler (1969) definió con el término de ageism a los estereotipos y discriminaciones contra las personas por el simple hecho de ser viejos, y explica que el único recurso para su disminución sería el conocimiento que otorga la educación (Butler, 1993). Sin embargo, estos prejuicios que se imponen sobre los cuerpos de las mujeres mayores son difíciles de romper cuando son definidos per se cómo no atractivos (Cruikshank, 2003).

La gerontología feminista y la psicogerontología se posicionan como una manera de conocer: la experiencia subjetiva del envejecer, el signifi ado del cuerpo, los problemas y las paradojas de la resistencia cultural (Twigg, 2004). La cultura occidental promueve el aprendizaje de sentimientos negativos acerca del envejecer y a empezar a experimentarlo de manera prematura, observando en el cuerpo de manera ansiosa los signos de decadencia y declive. De tal manera que esto genera estrategias de enmascaramiento y ocultamiento de la edad reforzando el "edadismo social" al retroalimentar de manera negativa de que hay algo en el cuerpo y en la vida de las mujeres mayores que debe ser ocultado, corroborando que envejecer es algo de lo cual hay que avergonzarse (Calasanti, 2004). Por lo que en la cultura occidental obsesionada por la juventud, los signos físicos del envejecer son una señal de fracaso personal, a lo cual a las mujeres les resulta difícil oponerse y resistir.

Por esto es urgente plantearse la necesidad de oponerse a las narraciones negativas del envejecimiento desde esta perspectiva dominante, resistiéndolas, lo cual implica elaborar diferentes lecturas, diferentes discursos, sobre el cuerpo, la edad, la belleza. Es necesario redefinir los modelos de belleza y combatir los estrechos límites de lo que se considera atractivo; pasar de una cultura anti age a una cultura pro age (Gullette, 2004). Es decir, generar procesos narrativos signifi ativos como consecuencia de haber sido dotados de signifi ado (Ramos, 2001). 
En otras áreas las mujeres han ganado terreno, el movimiento feminista abrió posibilidades, tal es el caso de su experiencia de vida en lo privado y lo público, diversas investigaciones han demostrado que en el caso de los roles tradicionales asignados a la mujeres (casa y familia) librarse de dos de los elementos que el patriarcado ha considerado fundamentales para su felicidad y realización (ser esposa, madre y ama de casa) se relaciona con un mayor sentimiento de felicidad, mejora de la autoestima y bienestar psicológico; en contra de la explicación que ha pretendido demostrar que la vida del hogar era un refugio de seguridad psicológica para las mujeres (Freixas, 1997).

Por otro lado, con respecto a la salud en esta etapa de vida, los estudios realizados concernientes a la menopausia indican que es necesario abordarlos desde una perspectiva crítica, en la que las mujeres puedan ser partícipes que reflejen la experiencia de diferentes culturas en torno a la menopausia; con un énfasis en la postmenopausia, periodo en el que las mujeres entran en una segunda edad adulta o en la tercera edad. Todo esto puede contribuir para orientar a las mujeres que se encuentran en este periodo de cambio y desvanecer muchas de las ideas que en estos momentos limitan y reducen su percepción de sí mismas, su cuerpo y las arroja a un mundo de mercado de anti-edad y de la eterna juventud (Freixas, 2004; 2007).

Ante este panorama la sororidad en los procesos de envejecimiento femenino se hace imperante; pues solo las mujeres pueden hacer visible lo invisible, es desde el territorio de la experiencia y la vivencia de las propias mujeres constructoras de sororidad que se podrán solventar deudas con ellas mismas. Es decir, un empoderamiento no sólo individual sino colectivo, el cual hace alusión al conjunto de capacidades de las mujeres para enfrentar como género la problemática de género, que se refleje en intercambio intergeneracional estrechando los puentes que vinculan y no que alejan (Lagarde, 2006), así también desde la trinchera académica, la mujeres tenemos que dar la voz a más mujeres, desarrollando alternativas feministas a la anulación patriarcal de las mujeres mayores, concediendo reconocimiento, autoridad y poder, proporcionando espacio y palabra, promoviendo una investigación ajustada a la realidad de las vidas de las mujeres que permita construir rituales habilitadores y positivos de representación de la vejez (Freixas, 2008).

Con lo anterior, el propósito de este trabajo fue describir y categorizar los tipos de configuraciones vinculares que se mantienen y los que se han transformado en pro a la sororidad en procesos de envejecimiento femenino.

\section{Método}

La elección del enfoque se decidió por el tipo de tratamiento que se le dará al objeto de estudio. Se eligió una metodología cualitativa, ya que ésta tiene como objetivo la descripción de las cualidades de un fenómeno, busca un concepto que pueda abarcar una parte de la realidad y no se trata de probar o de medir en qué grado una cierta cualidad se encuentra en un cierto acontecimiento dado, sino descubrir tantas cualidades como sea posible. Es decir, trata de conocer los hechos, procesos estructuras y personas en su totalidad, y no a través de la medición de algunos de sus elementos. La misma estrategia indica ya el empleo de procedimientos que dan un carácter único a las observaciones.

En investigaciones cualitativas se debe hablar de entendimiento en profundidad en lugar de exactitud, es decir, se trata de obtener un entendimiento lo más profundo posible.

Lo anterior se llevó a cabo a través de entrevistas a profundidad grupal, obteniendo así datos que ofrecieron información para entender la perspectiva del fenómeno estudiado. Por esto el método está basado en lo etno-metodológico, dado el tema y objeto de estudio, que consistió en examinar los modos en que las personas aplican las reglas culturales abstractas y percepciones de sentido común a situaciones concretas, para que las acciones aparezcan como rutinarias, explicables y carentes de ambigüedad. En consecuencia, los signifi ados son un logro práctico por parte de los miembros estudiados (Taylor \& Bogdan, 1987). 
La muestra estuvo compuesta por un grupo de mujeres en edades de 40 a 50 años participantes del Conversatorio "Hablar del Cuerpo desde otra mirada", el cual tuvo por objetivo conocer aspectos relacionados con la vivencia y experiencia de sororidad de las mujeres partícipes, así como la forma en que están relacionándose con sus propios cuerpos y los procesos de envejecimiento.

\section{Resultados}

\section{Categorización y Análisis}

\section{Experiencia en cuanto a su cuerpo}

Las participantes a través de sus diálogos construyeron de manera empírica lo que ya los teóricos hablan en relación al fenómeno denominado Matusalén (Hitzing, 2013; Magnus, 2009) que hace referencia sobre la manera distinta de verse a sí mismas en su proceso de envejecimiento en relación y comparación a como lo vieron o experimentaron otras mujeres, en especial mujeres de su propia familia. Así también refi ren como los constructos sociales de una sociedad del mercado del cuerpo de la mujer cobra factura a su propia autopercepción inclusive entre ellas mismas, concordando con lo que ya refi re Cruikshank (2003); Butler (1969; 1993) y Nelson (2004).

"Al ampliarse la esperanza de vida el cuerpo se va modificando, el cuerpo se vive de manera distinta".

"Lo hemos hecho cultural hemos adoptado prototipos de belleza de la TV, (delgadas, altas, rubias) son marcas referenciales de belleza.

Existe un fenómeno de la estética en las jóvenes que se preocupan al extremo en la belleza física.

"La cuestión social es tan fuerte que hace que uno dude de lo que uno piensa de si misma. En la cuestión laboral a uno le afecta el saberse "vieja" pues a partir de los 40 años ya no podemos encontrar trabajo tan fácil pues en la mayoría de los empleos buscan personas jó- venes y que cuenten con una belleza exterior la cual no se vea arrugada, aún cuando somos demasiado capaces y contemos con las habilidades para desarrollar el trabajo".

“Hay una invasión extranjera de cómo quieren ver a una mujer".

"Mi tía se hizo cirugía y al verla mi madre y verse a ella como que mi madre se sintió mal porque a ella si se le notan las arrugas, pero yo ya le dije que si desea hacerse cirugía lo haga".

"Mis hijos me están aceptando en esta etapa y me dicen "te amo así".

\section{Experiencia en cuanto a sororidad}

Aunque no era un término que la mayoría había escuchado, muchas refirieron tener experiencia con relación a esto. Sin embargo, existía la sensación de una iniciativa desde lo individual y asociado a un deseo más que algo que esté sucediendo. $Y$ se coincide con el concepto teórico que refi re un principio de reciprocidad que potencia la diversidad, en el cual se comparten recursos, tareas, acciones, éxitos y se aprende a reconocer el valor de manera igualitaria basado en el reconocimiento de la condición humana de todas las mujeres como participantes y activas de su propia vida (Lagarde, 2009).

"Sororidad, Hermandad, lazo de hermanas, se denomina el apoyo de una mujer hacia la otra, siendo empáticas".

"como tal, no había escuchado el término"

"No importa en qué te desarrolles, la clase social, nivel económico, debemos apoyarnos entre mujeres. Debemos crear un vínculo entre las mujeres".

\section{Importancia de sororidad en el proceso de envejecer y en las relaciones intergeneracionales}

Esta categoría hace referencia a esas experiencias y modos de vida que las identifi an y hacen dife- 
rentes a las mujeres. Pero sus diferencias no son tan importantes como para crear nuevas categorías de género, ya que comparten todas la misma condición histórica. Por tal razón es en conjunto que podrán desmitifi ar su condición de ser mujer (Lagarde, 2009; Riba, 2016).

“Acompañar a la mujer, juntas nos podemos apoyar; con mis hijas que tienen 28 y 22 años puedo compartir y aprender y en ese contacto también veo las limitaciones que tengo, veo lo que tengo y lo que puedo ser mejor y aprender de los demás".

"Empezar a compartir lo que eres y haces, partes desde donde estas parado, si se puede hacer si eres empática, ayudarnos en lugar de meternos el pie. No solo físicamente, puede ser que en mi caso y en mi lucha no ser la misma, pero desde mi lucha lo hago, lo impulso".

"Con mi madre he aplicado la sororidad, ella me tuvo a los 17 años y yo cuando ella tuvo su menopausia yo estaba chica pero tuve que investigar para ayudarla. Me sonó en el corazón que la tenía que ayudar, debía hacerlo, buscar algo, alternativas para darle alternativas de calidad de vida en su menopausia, en su alimentación. Ella empezó a los 55 años con otro proceso y tenía medicamento y tenía que regular ese proceso. Mis padres se fueron y mis compañeras me acogen en un círculo hermoso de amistad, hasta las mamás me aceptaban en esos núcleos familiares. Posteriormente cuando yo empiezo a trabajar después de los 30 años empiezo a trabajar con grupos de género".

\section{Cuerpo, envejecimiento y sexualidad de la mujer}

El estudio de la sexualidad de las mujeres mayores sigue siendo uno de los espacios de silencio más importantes, pero con poca investigación disponible y con insufi iente conocimiento que lo contraste (Howard, O’Neill \& Travers, 2006). Y sin embargo los primero estudios sobre sexualidad y vejez, muestran que los adultos mayores mantienen interés sostenido en la sexualidad a lo largo de toda la vida, y que en las mujeres el deseo sexual no decrece con el tiempo (Bretschneider \& McCoy, 1988; Masters \& Johnson, 1966).

Fue en la década de los años setentas, cuando las mujeres rompieron barreras y salieron a las calles y conquistaron espacios públicos. Sin embargo al correr el tiempo aún queda una batalla que pelear, el cuerpo femenino sigue siendo un callejón sin salida, en el cual la cultura de la juventud eterna, la sumisión a constructos patriarcales de subordinación a generando estragos contemporáneos de contra golpe a la libertad femenina (Wolf \& Moreno, 1991), y sin embargo las participantes reconocen que este es el territorio en el cual se viviría una libertad real, al ser mujer, sin miedos a embarazos no deseados, y a una conquista de sí mismas.

"Quiero compartir la experiencia de una tía de 85 años la cual ha vivido su sexualidad plenamente, nos platicaba a mis primas y a mi sus experiencias sexuales y como aún seguía disfrutando su sexualidad. Ella nos contaba estas experiencias sin pena, siempre me he visualizado el vivir mi vida como ella y yo cuando tenga su edad quiero ser como mi tía".

"Yo pienso que una adulta mayor no queda embarazada entonces eso sería una de las grandes ventajas para ellos de continuar con su vida sexual activa, pero antes de llegar a esa edad debemos conocernos para poder disfrutarnos con una mayor plenitud, ya que en tiempos anteriores o generaciones pasadas solo lo hacían por cumplir con sus responsabilidades de esposa lo cual al final resultaba ser una violación pues era algo que tu no querías ni disfrutabas. Para las mujeres era un alivio el que se terminara su edad reproductiva pues con esto se iba la vida sexual".

\section{Diferencias percibidas de la vivencia del envejecimiento a través del tiempo}

La carta magna de las mujeres postula construir la igualdad, lo cual conlleva un cambio profundo en lo que entendemos por ser mujer, es decir que implica una trasformación de las marcas, deberes, 
mandatos y sellos que obstaculizan el desarrollo pleno de nuestra vida, implica que no se trata de una homogeneidad de La Mujer, sino el respeto por la diversidad plural de Las Mujeres, con esto se entiende entonces que también habrá diversas formas de cómo envejecer, y este proceso se vivirá de acuerdo a la elección de cada una, y definitivamente la imagen del adulto mayor recluido y como un ser sabio recluido en el interior de la vida familiar va desapareciendo por un adulto mayor activo, propositivo, trabajador y que socializa (Zarebski, 2005).

"Social e históricamente la vejez se ha desarrollado como un constructo el cual vamos fomentando día a día, donde a raíz de esto la vemos como una etapa en la cual las personas ya no pueden seguirse desempeñando libremente y dependen de las demás personas que se encuentran a su alrededor.

La manera de visualizarnos en el envejecimiento tiene que ver con la esperanza de vida que antes se tenía, debido a esto todos tenemos en la mente claro por qué no queremos envejecer.

Pero una verdad es que no necesariamente tenemos que llegar a ser de esos viejos dependientes, sino que podemos seguir disfrutando de la vida, disfrutarnos en nuestras actividades y seguir siendo personas productivas para la sociedad pero principalmente funcionales para nosotros mismos".

\section{Su aportación a una nueva construcción del envejecimiento}

En lo que las participantes compartieron hubo coincidencia con la perspectiva psicogerontológica y la gerontología feminista sobre el proceso de envejecer, que postulan la necesidad de preparase para la vejez cuando se es joven, y así se estaría realizando un empoderamiento de la mujer mayor, pues como ya se mencionó, la vejez es el resultado de lo que se ha vivido, y lo que se ha decidido en etapas anteriores, en lo afectivo, en lo físico y en lo social (Hierro, 2004).
"La mayoría de la piel no es la misma, hay celulitis, flacidez, la piel no es la misma, pero viene una especie de sabiduría y aceptación. Por más bien formada que estés te viene los cambios y la factura... es la factura por llegar a la vejez y aprender a querer tu cuerpo y cambia la perspectiva que bonito que puedas vivirlo, disfrutarlo, enfrentarlo, verme al espejo más relajada y con mucho mejor calidad de vida. Si el día de mañana llega alguien y me acepta que bueno y si no pues ni modo".

"Cómo debe vivirse este momento de envejecer?, el presente es el reflejo de tu pasado, he vivido 34 años de matrimonio de manera plena aunque mi esposo no quiera hacer las cosas yo hago lo que yo quiero y con lo que yo me siento bien. No me quiero ver como mi mamá".

"Yo a diferencia de usted si me quiero ver como mi mamá, ella siempre ha sido una mujer muy independiente, quiero realizarme en todas las áreas que integran mi vida".

"Sentirme bien, satisfecha, estoy a gusto con lo que soy. Vivir aquí y ahora. Satisfacción. Vivir intensamente me hará vivir un futuro más agradable. Depende del cristal con que se mire la misma historia. Superarme a mí misma, si no me gusta, hago porque me guste o busco. Llegar a adultos mayores generando sororidad".

\section{Cómo se asumen como constructoras de sororidad}

En el movimiento feminista fue necesario establecer un pacto entre mujeres que diera dirección a los esfuerzos que se llevaban a cabo por cada una en diferentes ámbitos y en diferentes territorios. Este pacto permitió el reconocimiento en primer lugar, que la enemistad entre el género no es natural sino construido y que alimenta el orden simbólico androcéntrico, por lo cual, es ineludible apoyarse las unas con las otras. Este es el núcleo del concepto sororidad, acuñado por Marcel Lagarde: 
(...) pacto político de género entre mujeres que se reconocen como interlocutoras. No hay jerarquía, sino un reconocimiento de la autoridad de cada una. Está basado en el principio de la equivalencia humana, igual valor entre todas las personas porque si tu valor es disminuido por efecto de género, también es disminuido el género en sí (2009, s.p.).

Este es el camino para generar entre nosotras modos distintos de convivencia, inclusive el término no es privativo a la mujer, a lo cual las practicantes expresaron lo siguiente:

"Todas las mujeres somos o debemos ser provocadoras de la sororidad. Debemos permitirnos ser y dar para poder generar sororidad. La sororidad se conforma según los grupos en los que nos desenvolvemos, ya que tengo muchos grupos pero cada uno es diferente".

"Puedo ser provocadora de sororidad, me permito más y disfruto más mi femineidad, podemos estar en un ambiente hostil y formar parte de él o provocar sororidad. Me doy cuenta que tengo esa capacidad de provocar que cambie un ambiente hostil. Cuando veo resultados creo que valió la pena aguantar el proceso".

"Debemos superarnos a nosotras mismas. Debemos llegar a la vejez practicando la sororidad para aportar nuestro granito de arena hacia la sociedad pero sobre todo a nuestras demás mujeres hermanas, las cuales en lugar de truncar nuestro camino debemos ayudar a fortalecerlo".

\section{Propuesta de intervención desde el modelo de la narrativa de White.}

Derivado de lo anterior se diseñó un taller para trabajar los procesos de envejecimiento con perspectiva de género, con el fin de construir sororidad y significación al proceso que se experimenta en el cuerpo el envejecimiento por las mujeres. A continuación, se describe la propuesta del taller denominado REESCRIBIENDO MI CUERPO.

\section{Nombre del taller: “ENCONTRANDO MI CUERPO”}

El taller está basado en el modelo de la narrativa del enfoque sistémico de White y Epston (1993) en el cual se plantea que las historias que crean las personas sobre sus vidas determinan, tanto la atribución de signifi ado a sus vivencias, como la selección de los aspectos de la experiencia que van a expresarse, estos relatos son constitutivos o moldeadores de la vida de las personas., planificado en seis sesiones: 1) Reconociendo mi cuerpo, 2) Saludando a mi cuerpo, 3) Carta a mi cuerpo: Hola mi cuerpo es..., 4) Hoy decido..., 5) La celebración, 6) Clausura: Reconociendo el logro (Ver Tabla 1).

Tabla 1.

Hoja descriptiva del taller basado en el modelo de la narrativa.

\begin{tabular}{llll}
\hline Dirigido a: & Mujeres a partir de 40 años de edad. \\
\hline $\begin{array}{l}\text { Denominación de la } \\
\text { Técnica }\end{array}$ & Técnicas & Duración & Objetivo \\
\hline $\begin{array}{l}\text { Sesión 1: } \\
\text { Reconociendo mi } \\
\text { cuerpo }\end{array}$ & $\begin{array}{l}\text { Visualización e } \\
\text { Imaginería guiada }\end{array}$ & 60 min. & $\begin{array}{l}\text { Elaborar con las mujeres participantes una } \\
\text { historia de su cuerpo. }\end{array}$ \\
\hline $\begin{array}{l}\text { Sesión 2: } \\
\text { Saludando a mi } \\
\text { cuerpo }\end{array}$ & Externalización & 180 min. & $\begin{array}{l}\text { Estimular el uso del lenguaje coloquial, poético y } \\
\text { pintoresco en la descripción de vivencias y en el } \\
\text { intento de construir nuevos relatos a través del } \\
\text { dibujo, máscaras o historias. }\end{array}$ \\
\hline
\end{tabular}




\begin{tabular}{|c|c|c|c|}
\hline $\begin{array}{l}\text { Denominación de la } \\
\text { Técnica }\end{array}$ & Técnicas & Duración & Objetivo \\
\hline $\begin{array}{l}\text { Sesión 3: } \\
\text { Carta a mi cuerpo: } \\
\text { Hola mi cuerpo es... }\end{array}$ & $\begin{array}{l}\text { Re-escritura de } \\
\text { historia alternativa }\end{array}$ & $90 \mathrm{~min}$. & $\begin{array}{l}\text { Permitir descubrir acontecimientos extraordinarios } \\
\text { que han quedado fuera de la historia oficial } \\
\text { y estimular a las mujeres a que de un nuevo } \\
\text { significado con relación a sí misma, y su cuerpo, } \\
\text { como a las relaciones con los demás. }\end{array}$ \\
\hline $\begin{array}{l}\text { Sesión 4: } \\
\text { Hoy decido... }\end{array}$ & Testigos externos & $90 \mathrm{~min}$. & $\begin{array}{l}\text { Construir la identidad a través de contar y } \\
\text { recontar la historia nueva que surgido del } \\
\text { cuerpo: Nuevo reconocido con la finalidad de } \\
\text { validar y fortalecer las historias de las mujeres } \\
\text { participantes frente a las otras. }\end{array}$ \\
\hline $\begin{array}{l}\text { Sesión 5: } \\
\text { La celebración }\end{array}$ & Ritual curativo & $90 \mathrm{~min}$. & $\begin{array}{l}\text { Se pretende mediante acciones simbólicas disipar } \\
\text { o transformar las imágenes negativas del cuerpo } \\
\text { que habían sido narradas en la historia original. }\end{array}$ \\
\hline $\begin{array}{l}\text { Sesión 6: } \\
\text { Clausura: } \\
\text { Reconociendo el logro }\end{array}$ & $\begin{array}{l}\text { Ceremonia } \\
\text { Coronación Clausura } \\
\text { y Certificado }\end{array}$ & $60 \mathrm{~min}$. & $\begin{array}{l}\text { El terapeuta otorga un certificado o diplomado } \\
\text { haciendo énfasis en los logros de las mujeres y el } \\
\text { grupo }\end{array}$ \\
\hline
\end{tabular}

Fuente: elaboración propia

\section{Proceso de cada sesión que conforma el taller}

En la primera sesión denominada Reconociendo mi cuerpo se trabaja mediante las técnicas de visualización e imaginería que nos permita elaborar con las participantes una historia de la relación con su cuerpo y lograr construir una narración colectiva que pueda estar cargada de signifi aciones y construcciones sociales de la manera en que se vive y experimenta el cuerpo y su proceso de envejecimiento (la historia del problema). White y Epston (1993) creen que la gente se enfrenta a difi ultades cuando vive con historias dominantes que están saturadas de ideologías patriarcales. Estas historias dominantes son restrictivas, no abarcan partes importantes de la experiencia de las mujeres y las llevan a llegar a conclusiones negativas sobre su cuerpo y su propia identidad.

Para lograr lo anterior se utilizan las denominadas preguntas "Panorama de la Acción", las cuales enfocan eventos específi os y su ocurrencia en la historia reciente y lejana: ¿cuándo se presenta en tú vida la vivencia de tu cuerpo y su proceso de envejecimiento?; ¿qué áreas de tú vida consigue dominar?; ¿cómo te convence que lo escuches?; ¿de qué se disfraza para lograr que lo escuches?; ¿cómo ha afectado la manera de ver tu cuerpo en las relaciones con tus familiares, amigas, compañeras de trabajo, etc?; ¿cómo logra arruinar tus actividades?

La segunda sesión denominada Saludando a mi cuerpo tiene la intención de estimular el uso del lenguaje coloquial, poético y pintoresco en la descripción de vivencias y en el intento de construir nuevos relatos a través del arte y el juego como el dibujo, máscaras o historias; logrando la externalizacion del problema (White y Epston, 1993).

Morgan (2000) refi re que cuando la gente empieza a hablar de sus problemas como entidades separadas, como algo que está afuera, siente una diferencia casi inmediata. Con frecuencia reportan que externalizar los problemas les ayuda a ponerlos en perspectiva, a sentirse menos culpables y a sentir que pueden hacer algo para solucionarlos.

También, explica que las conversaciones exteriorizadas constan de los siguientes pasos: nombrar al problema, explorar los efectos del problema sobre la vida de la persona y desconstruir o poner en contexto el problema. Cuando hablamos de nombrar al problema, en la terapia narrativa, es muy importante trabajar con las palabras exactas 
que usa el paciente y se puede invitar también a compartir imágenes o metáforas que describan al problema.

En relación a desconstruir o poner el problema en contexto, en la terapia narrativa se exploran también los efectos que tienen los discursos y prácticas sociales dominantes en la vida de las mujeres que participan de este taller. Dentro del taller basado en el modelo de la narrativa es en el nivel de la reflexión donde se logra el análisis que los logros aislados tienen sobre los deseos, intenciones y compromisos de la persona y sus relaciones.

Una de las características más sobresalientes de la psicoterapia de narrativa es la recuperación de la persona, como su propio agente o sujeto. A través de la externalización y la incorporación de la influencia personal sobre el problema (acontecimientos extraordinarios) se crea una contratrama que incluye como personaje central a la persona construyendo (re-editando) nuevas acciones que demuestran su fuerza y poder.

En la tercera sesión denominada Carta a mi cuerpo: Hola mi cuerpo es... con el objetivo de permitir descubrir acontecimientos extraordinarios que han quedado fuera de la historia ofi ial y estimular a la persona a que de un nuevo signifi ado con relación a sí misma, a su cuerpo, como a las relaciones con otras mujeres.

Se le induce a través de la visualización tal como lo menciona De Shazer (1995). para que logre imaginarse sin el problema y como seria su vida a partir de ese momento para poder iniciar con la reescritura de la historia alternativa. Para esto se pide que de manera colectiva se escriba una carta colectiva al cuerpo de la mujer. La cual será leída y además utilizando nuevamente el juego y el arte se diseñan de manera creativa su diseño. La carta colectiva tiene como objetivo ser un testimonio de la nueva relación que se desea vivir con el cuerpo propio y colectivo de las mujeres, en donde queda implícita una complicidad en la construcción de la sororidad femenina. Es necesario continuar con preguntas relacionadas con el sistema relacional:
¿Quién se daría cuenta de tu cambio? ¿Cómo sabrías tú que se dio cuenta?, ¿se comportaría de un modo diferente esa persona al ver tu cambio?

A la vez esta intervención permitirá que la persona logre fortalecer su agencia personal, se refiere según White y Epston, (1993) a la posibilidad de tomar e implementar decisiones que posibiliten lo que como mujeres desean lograr en la vida, a lo que preferirían hacer y cómo les gustaría ser. White y Epston con frecuencia usan la metáfora de Ir en el asiento del conductor de la propia vida. La carta colectiva, de acuerdo a White y Epston (1993) pueden contribuir a fortalecer una propuesta de sororidad creativa.

La cuarta sesión denominada Hoy decido tiene la finalidad de construir la identidad a través de contar y recontar la historia de las mujeres con el propósito de validar y fortalecer sus historias frente a testigos externos; éstos son las futuras generaciones de mujeres que vienen tras de ellas y a las cuales se desea trasferir una manera más sana y solidaria con el linaje de mujeres, libres de pesos patriarcales que reducen la visión entre ellas mismas y de ella mismas.

Tal como lo menciona White y Epston (1993) propone que en la terapia se pueden implementar prácticas que sirvan como ceremonias de definición que contribuyen a validar y fortalecer las historias, en este caso de las mujeres.

White (2007) diseñó un mapa en el que describe detalladamente los pasos de las ceremonias de definición en la terapia, principalmente el objetivo de este tipo de ceremonias de definición es conectar las historias y las vidas de las personas. Tener testigos al contar la historia propia puede hacer que ésta sea más signifi ativa. Esto es especialmente importante cuando se trata de contar historias alternativas que estamos tratando de establecer y cultivar en el contexto de otras historias dominantes que ya están arraigadas y que influyen de manera negativa sobre la identidad.

La quinta y sexta sesión tiene por objetivo reafirmar los logros a través de rituales terapéuticos en el cual se expiden documentos que afirman lo anterior. 


\section{Discusión}

Los hallazgos de este trabajo describen la necesidad de implementar políticas y acciones en aras a disminuir el agaism no solo con relación a lo que se vive como mujeres, sino con relación al envejecimiento en general. Las diversas investigaciones referentes a este fenómeno social de discriminación y estereotipos negativos conocidos como viejísimos también alertan sobre la tendencia a una representatividad del concepto general, formulado en un constructo social, injustifi ado y falso de una realidad denominada vejez, cada día más vinculado al envejecimiento sano y constructivo (Fernández-Ballesteros, 1992; San Román Espinosa, 1990; Seymour, 1991; Toledo, 2011).

Una de las medidas es sin duda alguna la construcción de la sororidad en círculo de mujeres, que las lleve a un empoderamiento colectivo en pro de su género. La política feminista exhorta a la sororidad como pacto político de género entre mujeres que se reconocen como interlocutoras. En el cual no existen jerarquías, sino un reconocimiento de la autoridad en cada mujer. Este pacto se basa en el principio de la equivalencia humana, igual valor entre todas las personas. En ocasiones, la lógica patriarcal nos impide ver esto (Lagarde, 2009).

El envejecimiento sin duda se vive y experimenta desde la subjetividad, pero esta vivencia tiene un impacto en la colectividad de mujeres, por esto la importancia de fomentar sororidad a través de las relaciones intergeneracionales. Pues las trasformaciones que se hagan en una generación pasaran a la siguiente por tanto, la importancia de trabajar en colectivo, tal cual lo expresa Marcela Lagarde:

Juntas, vamos construyendo un modelo porque de la experiencia de una mujer nos benefi iamos todas. Aunque ni lo sepamos, cambios que hacemos en nuestras vidas los hemos tomado de otras. Después, llegará alguien que a todo esto le ponga indicadores, el nombre de plan, de programa... y estas experiencias tendrán la sistematización que requieren. Todas somos diversas, incluso entre cada una misma según el momento de la vida en el que se encuentre (Lagarde, 2009, p 2).
El cuerpo femenino se constituye un foco de atención en lo referente a cómo vive y experimenta este proceso las mujeres, los cuerpos femeninos siguen siendo un territorio para conquistarse.

Unido a la anterior afirmación, la sexualidad en las mujeres en la mediana edad o como adultas mayores, es considerado como un derecho a seguir experimentado amor y vida sexual, así como que pueden iniciar una relación afectiva tras enviudar (Hernández, 2008). El amor y la sexualidad son aspectos de gran importancia para el ser humano, aún en la vejez teniendo un impacto importante en la percepción de la propia calidad de vida (Freixas \& Luque, 2014) y como lo explica Guadarrama, Ortiz, Moreno y González (2010). Sin embargo, cada generación tiene percepciones distintas respecto a la misma, las cuales pueden limitar o favorecer su expresión y disfrute, razón por lo cual es un aspecto para trabajarse, investigarse, intervenirse.

\section{Conclusiones}

1. De manera empírica se comprueba las diferencias histórico social y cultural en la manera de percibir el proceso de envejecer de las mujeres, al compararse ellas con mujeres de otras generaciones.

2. La sororidad se experimenta más como un deseo, un ideal en la convivencia femenina más que algo que se de en la práctica cotidiana.

3. A pesar de la existencia de diferencias individuales en los propios procesos de envejecimiento, las mujeres se experimentan y comparten en una misma condición histórica. Por esto, es en colectivo que la acción de la sororidad se pronuncia como vía en las nuevas narrativas y las nuevas identidades preferidas de las mujeres.

4. La sexualidad en la etapa de adulto mayor sigue siendo un asunto pendiente a atender en la agenda de investigación.

5. Así como existen diversas maneras de vivirse como mujer, las hay para envejecer, por esto es necesario coadyuvar en brindar los espacios de expresión libre en la elección del cómo se 
prefiere experimentar los propios procesos de envejecimiento.

6. Surge la idea de construir la vejez femenina desde edades jóvenes, como una postura política y ética de empoderamiento de la mujer mayor.

7. La construcción de una cultura de la sororidad ha permitido reconocer que la enemistad entre mujeres es algo no natural, por lo cual, es imperioso visibilizar las prácticas que sí rescatan las historias de relaciones de colaboración fraterna entre mujeres.

\section{Referencias}

Bretschneider, J. G. \& McCoy, N. L. (1988). Sexual interest and behavior in healthy 80 - to $102-$ years-olds. Archives of Sexual Behavior, 17(2), 109-129.

Butler, R. (1969). Ageism: Another form of bigotry. The Gerontolist, 9, 243-246.

Butler, R. (1993). Dispelling ageism: The crosscutting intervention. Generations, Spring/ Summer, 75-78.

Calasanti, T. (2004). New directions in feminist gerontology: An introduction. Journal of Aging Studies, 18, 1-8.

Cruikshank, M. (2003). Learning to be old. Gender, culture, and aging. Lanham: Rowman \& Littlefield.

De Shazer, S. (1995). Claves para la solución en terapia breve. Barcelona: Paidós.

Fernández-Ballesteros, R. (1992). Mitos y realidades sobre la vejez y la salud, Barcelona: SGFundación Caja Madrid.

Freixas, A. F. (1997). Envejecimiento y género: otras perspectivas necesarias. Anuario de Psicología, 75(2), 31-42.

Freixas, A. F. (2004). Envejecimiento y perspectiva de género. En Ester Barberá \& Isabel Martínez Benlloch (Eds.), Psicología y género (pp. 325-352). Madrid: Pearson.
Freixas, A. F. (2008). La vida de las mujeres mayores a la luz de la investigación gerontológica feminista. Anuario de psicología/The UB Journal of psychology, 39(1), 41-57.

Freixas, A. F. (2007). Nuestra menopausia. Una versión no oficial. Barcelona: Paidós.

Freixas, A. \& Luque, B. (2014). La sexualidad de las mujeres mayores. Perspectiva evolutiva y psicosocial. Anuario de Psicología, 44(2) 213-228.

Guadarrama, R., Ortiz, M., Moreno, Y. \& Gonzales, A. (2010). Características de la actividad sexual de los adultos mayores y su relación con su calidad de vida. Revista de especialidades médico-quirúrgicas, 15 (2), 72-79.

Gullette, M. M. (2004). Aged by culture. Chicago: The University of Chicago Press.

Hernández, Z. (2008). Algunos aspectos a considerar sobre la sexualidad en el adulto mayor. $E l$ ágora USB, 8, 375-387.

Hierro, G. (2004). Las mujeres y sus sexualidades una ética sexual feminista para la madurez. Chapa. H. M (Ed.) Envejecer con Dignidad, (pp.73-81). Nuevo León, México: Gobierno del Estado de Nuevo León. Recuperado de http:// www.nuevoleon.gob.mx/sites/default/files/ envejecer_con_dignidad-planchas.pdf

Hitzig, J. (2013). Abordajes Psiquiátricos y Psicofármacos $I$. Material didáctico del módulo de formación en psicogerontologia. Buenos Aires Argentina: Universidad Maimónides.

Howard, J.R., O’Neill, S., \& Travers, C. (2006). Factors affecting sexuality in older Australian women: Sexual interest, sexual arousal, relationships and sexual distress in older Australian women. Climateric, 9, 355-367.

Masters, W.H. \& Johnson, V.E. (1966). Human sexual response. Boston: Little Brown.

Lagarde, M. (1997). La política de las mujeres. Madrid: Cátedra. 
Lagarde, M. (2006). Pacto entre mujeres. Sororidad. Ponencia leída en Madrid (10 de octubre), en pmayobre/textos/marcela_lagarde _y_de_los_-rios/sororidad. pdf (consultado: 5 de abril).

Lagarde, M. (2009). La política feminista de la sororidad. Mujeres en Red, El Periódico Feminista, 11.

Lagarde, M. Conferencia sobre la Sororidad. En Youtube. 21 de abril de 2013.

Morgan, A. (2000). Qué es la terapia narrativa. Disponible en: www.dulwichcentre.com.au/ que-es-la-terapia-narrativa.pdf

Magnus, G. (2009). La era del envejecimiento. México: Océano.

Morin, E. (2004). El Método, Tomo 6. La Ética. Paris: Seuil.

Nelson, T. D. (2004). Ageism: Stereotyping and prejudice against older persons. Cambridge: MIT press.Pagaza, A. A. (2014, Marzo,8). La reparación antes de pensar una política de sororidad. Folleto Temático: Sororidad posibilidad de resignificación y coexistencia entre mujeres. México: Universidad intercontinental. Recuperado de https://docslide.net/ documents/xi-sororidad-posibilidad-de-resignificacion-y-coexistencia-entre-las-mujeres. html

Ramos, R. (2001). Narrativas contadas, narraciones vividas. Un enfoque sistémico de la terapia narrativa. España: Paidós.

Riba, L. (2016). Memoriales de mujeres: la sororidad como experiencia de empoderamiento para resistir a la violencia patriarcal. Franciscanum. Revista de las Ciencias del Espíritu., 58(165), 225-262.

Salvarezza, L. (1988). Viejísmo. Los prejuicios contra la vejez. Psicogeriatría. Teoría y Clínica. Buenos Aires. Paidós.

San Román Espinosa, T. (1990). Vejez y Cultura. Hacia los límites del sistema. Barcelona: Fundació Caixa de Pensions

Seymour, M. (1991). Demasiado viejo para la atención. Canadian Nurse, 26-27.

Taylor, S. J., \& Bogdan, R. (1987). Introducción a los métodos cualitativos de investigación. España: Paidos.

Toledo, A. M. (2011). Viejismo (ageism). Percepciones de la población acerca de la tercera edad: estereotipos, actitudes e implicaciones sociales. Revista Poiésis, 10(19), 1-10. Recuperado de http://www.funlam.edu.co/poiesis

Twigg, J. (2004). The body, gender, and age: Feminist insights in social gerontology. Journal of Aging Studies, 18(1), 59-73.

White, M. \& Epston, D. (1993). Medios narrativos para fines terapéuticos. Barcelona: Paidos.

White, M. (2007). Maps of narrative practice. New York: W.W. Norton \& Co.

Wolf, N., \& Moreno, L. (1991). El mito de la belleza. Barcelona: Emecé.

Zarebski G. (2005). Psicogerontología: Hacia un Buen Envejecer. 159 - 176. Buenos. Aires. Universidad Maimónides 